Hellstedt, M. (2020): Detection of odour from animal production in Finland. Agriculture and Forestry, 66 (1): 07-14.

Maarit HELLSTEDT ${ }^{1}$

DOI: 10.17707/AgricultForest.66.1.01

\title{
DETECTION OF ODOUR FROM ANIMAL PRODUCTION IN FINLAND
}

\begin{abstract}
SUMMARY
Agriculture is the most significant source of ammonia emissions. These emissions cause, for example, odour problems, which are a local nuisance to neighborhoods, and acidification. Traditionally, animal production farms have been situated in rural areas far from densely populated areas. However, as urban areas grow, the urban population is moving nearer to these farms. Problems arise when farms need to grow or change their production and their neighbors oppose this due to the potential for odour. Thus, odour annoyance must be taken into account when providing environmental permissions for animal production units. Two different estimation methods are used in Finland. The first is a curve based on the number of livestock units in the production unit. The second, which is still under development, is a model based on animal- and production-dependent odour factors, the prevailing wind direction and the topography of the area. However, both methods have deficiencies. When the production unit has already been established, prevailing odour can be measured with an olfactometric method based on the odour sensations of a panel of people with different sensitivities to odour annoyance. The olfactometric method can also be used to estimate the effect of different production technologies on odour. Examples of applications of the olfactometric method are presented.
\end{abstract}

Keywords: Animal production, odour, annoyance, measurement.

\section{INTRODUCTION}

Agriculture is the most significant source of Ammonia emission that causes e.g. odour problems. Animal production farms have traditionally been situated in the rural areas well apart from densely populated urban areas. As urban areas grow, new transition zones where farms, urban population and e.g. recreation seek for their own space and how to fit together. Problems arise when farms need to grow or change their production and neighbors oppose the environmental permit due to expected odour annoyance. Problems also arise where cultivated fields are situated near urban areas and the farmer wants to use manure as fertilizer to the fields (Hellstedt and Haapala, 2014). Animal production farms applying environmental permission often face an odour emission challenge.

\footnotetext{
${ }^{1}$ Maarit Hellstedt (corresponding author: maarit.hellstedt@luke.fi), Production systems, Natural Resources Institute, FINLAND

Paper presented at the $10^{\text {th }}$ International Scientific Agricultural Symposium "AGROSYM 2019". Notes: The authors declare that they have no conflicts of interest. Authorship Form signed online. Received:16/10/2019 
Odour annoyance has to be taken into account on the environmental permissions for animal production units.

There are two different estimation methods used in Finland. The first simple one is a curve that is based on the number of livestock units in the production unit. The other one, still under development, is a model that is based on animal and production dependent odour factors, prevailing wind directions and topography of the area. Both of these methods have deficiencies.

There are, however, methods available for reducing the odor level of animal production. Directive on industrial emissions (European Parliament and Council, 2010) defines Best Available Techniques (BAT) which are feasible for reducing environmental emissions. A Reference Document (Santonja et al. 2017) is updated on a regular basis where the available BAT technologies are listed. The challenge for the farmer is to prove that the techniques planned to be used have the odour reducing effect expected. There are available equipment to measure the components causing odour. These mainly on research purposes developed measuring methods are slow and expensive. Practical methods with affordable equipment and straightforward calculations are needed.

The main source of odour in animal farms is manure. The odour increases steeply as the temperature of manure gets higher (Hügle and Andree, 2001). The effect is steeper with pig manure than with cattle manure, Figure 1. Therefore techniques which cool down the inside air in production units could reduce odour emission especially from swineries. In the inside air of an animal houses dust particles and odour particles are of the same size and interlocked. Consequently, high-pressure spraying that both cools the air down but also reduces dust could also reduce the odour.

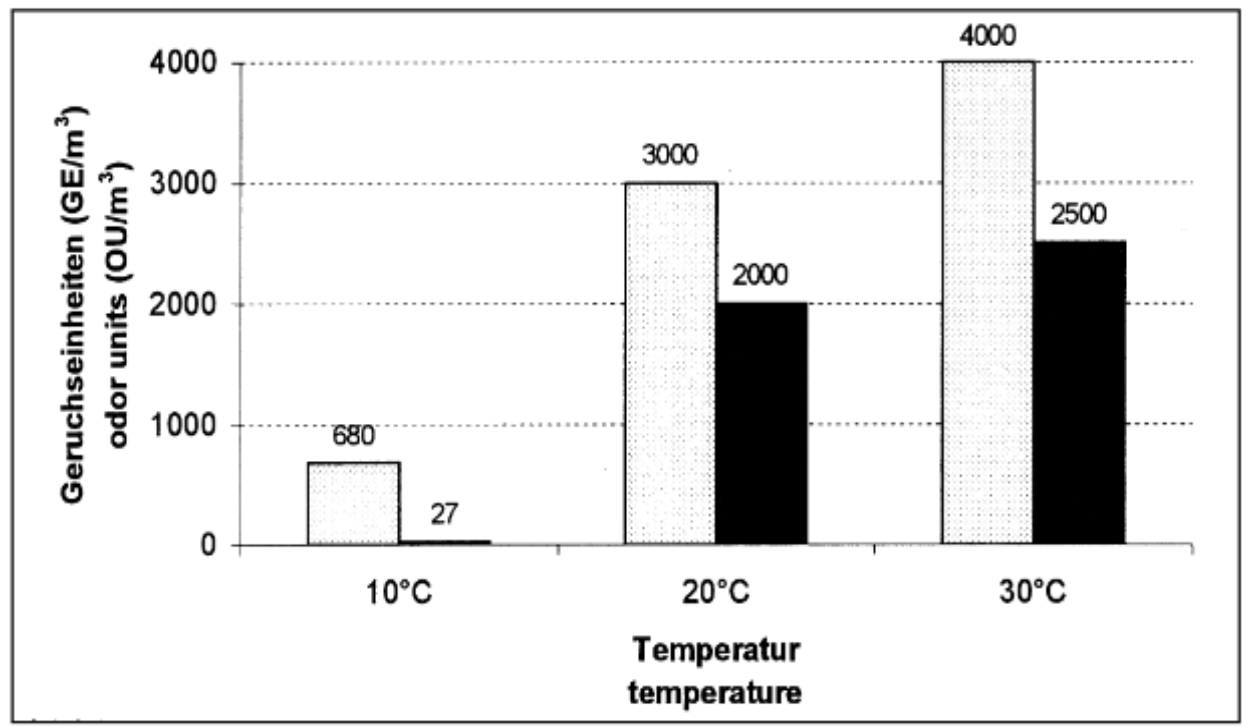

Figure 1. Odour concentration (OU/m3) of swine- (white) and cattle (black) slurry at different temperatures (Hügle and Andree, 2001). 
Recent research projects have aimed to create practical methods to measure the annoyance of odour from a production unit in practical situations and to prove the effect of different new environmental technologies on the odour. In this paper results from three different practical measurements are reported.

\section{MATERIAL AND METHODS}

The prevailing odour from an established production unit was detected from two different farms, a broiler farm and a swinery, near an urban area using an odour panel, Figure 2. The sensitivity of panelists was tested individually according a specific procedure (Pen-Test). Applying the protocol suggested by Brand et al. (2011) and more detailed described in Hellstedt and Haapala (2014) the panelists approached the source of odour from different directions defined according to the prevailing wind direction in the area, Figure 3.

Measurements to estimate the effect of different production technologies on odour were performed in a new swinery that has invested in different environmental technologies. The farm produces ca. 3000 fattening pigs annually. The technology inside the production unit tested was a high-pressure water spraying system. The high-pressure water spraying is originally designed to cool down the inside air in the swinery. But it also reduces dust that otherwise would be carried through ventilation. Two compartments of the swinery were used. One compartment had the technology on and the other one off. Odour measurements were done at three different locations along the central aisle of the compartment. Pellon Biosampo ${ }^{\mathrm{TM}}$ was used to treat manure on the swinery. The treatment had a notable effect on the odour level of the slurry. To measure the effect, a test was done. Raw slurry was taken directly from the buffer storage before the treatment plant and the treated liquid fraction was taken from the last treatment tank. Both the spread liquids were fresh. The characterization of the materials is shown in table 1.

Broadcast spreader with a splash plate was used for spreading both the raw slurry and the treated liquid fraction. The spreading area was about 1 ha. The weather was sunny, temperature $+12{ }^{\circ} \mathrm{C}$ and wind speed ca. $5 \mathrm{~m} / \mathrm{s}$. Odour measurement were done at a corner of the spreading area under the prevailing wind.

Table 1. The nutrient and dry matter content of the raw slurry and treated liquid fraction.

\begin{tabular}{|l|c|c|c|c|c|}
\hline & $\begin{array}{c}\mathrm{N}_{\text {tot }} \\
\mathrm{g} / \mathrm{kg}\end{array}$ & $\begin{array}{c}\mathrm{N}_{\mathrm{sol}} \\
\mathrm{g} / \mathrm{kg}\end{array}$ & $\begin{array}{c}\mathrm{P} \\
\mathrm{g} / \mathrm{kg}\end{array}$ & $\begin{array}{c}\mathrm{K} \\
\mathrm{g} / \mathrm{kg}\end{array}$ & $\begin{array}{c}\text { Total } \\
\text { solids } \\
\%\end{array}$ \\
\hline Raw slurry & 4.1 & 3.1 & 0.57 & 2.4 & 2.85 \\
\hline $\begin{array}{l}\text { Treated liquid } \\
\text { fraction }\end{array}$ & 2.9 & 2.2 & 0.24 & 1.8 & 1.27 \\
\hline
\end{tabular}




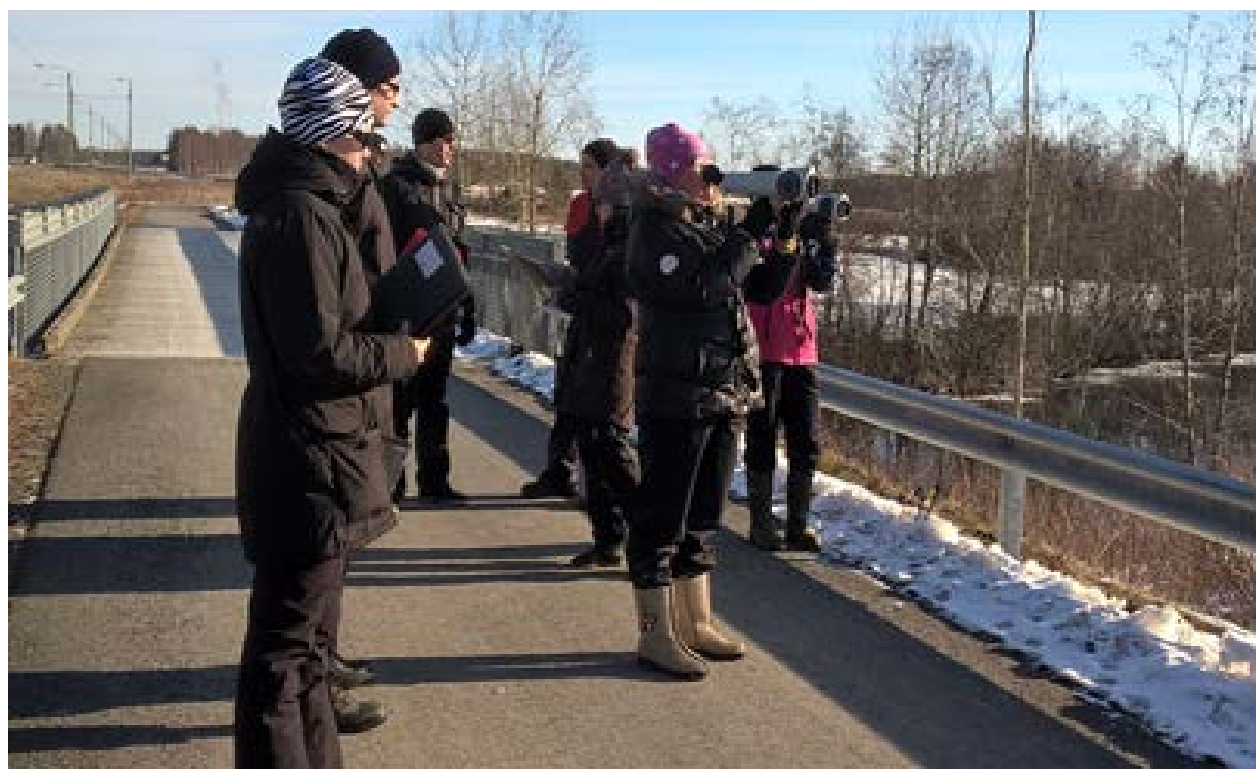

Figure 2. Persons of the odour panel approaching the source of odour.

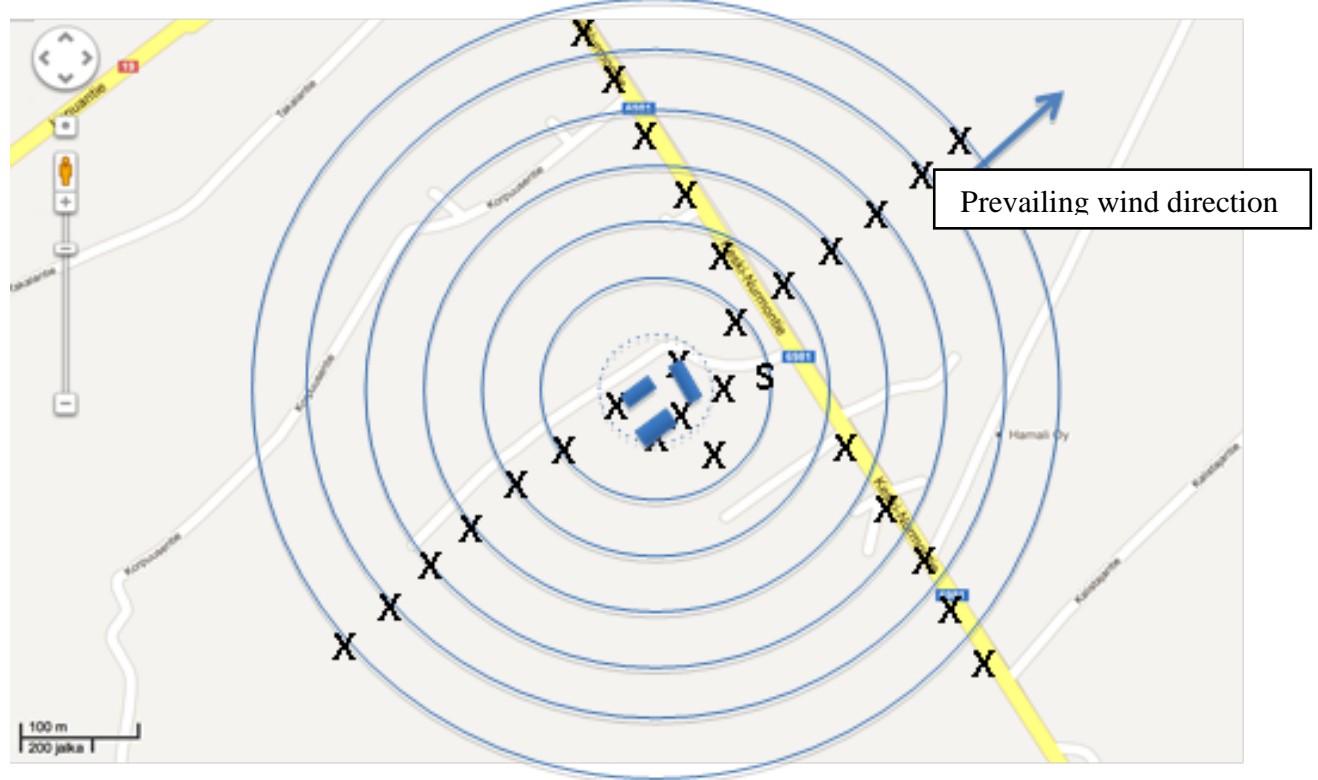

Figure 3. Principle of the odour panel method, $\mathrm{x}$ stands for the different locations were the odour measurements were carried out.

In all these cases odour emission was measured with an olfactometric method that is based on odour sensation of a person, Figure 4a. A Nasal Ranger $^{\mathrm{TM}}$ field olfactometer was used. The odour was measured as odour 
concentration, expressing the amount of dilution needed to make the air odourless, Figure 4b. Also the character of the odour was assessed in most of the cases.
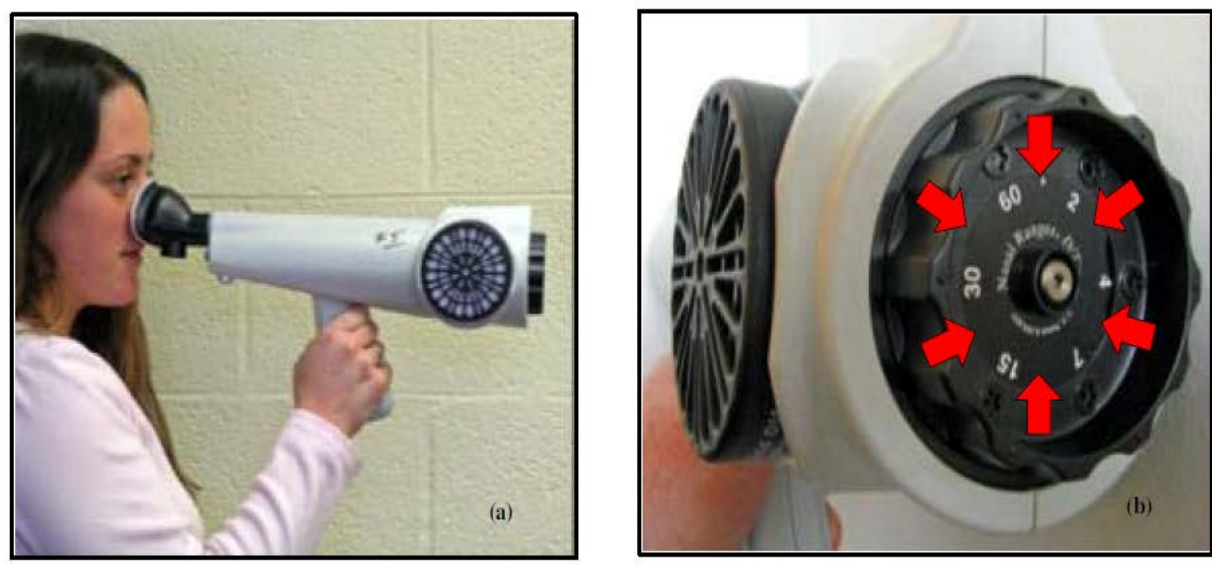

Figure 4. (a) The field olfactometer in use. (b) The dilution dial located at the air intake of the unit, which is unseen by the odour assessor during use (100\% active carbon-filtered air blank positions are marked with arrows). Nasal Ranger (2013).

\section{RESULTS AND DISCUSSION}

The results of the odour panel show that the odour from the farm was found stronger on areas which are situated downwind from the production unit, Figure 5. Odour was also found slightly at intervals in other directions because the wind was quite low and the odour fall down all around the farm. The forest area next to the swinery seems to prevent the odour to spread into that direction. The odour from a broiler farm was found less annoying than that from a fattening pig farm.

According to the results the high-pressure water sprayer reduces odour as it cools down the inside air in the swinery. The reduction of odour level measured is significant ( $>$ $>67 \%$ ) during the spraying, Figure 6. Until now these sprayers have been sold to farms on the basis of animal welfare. Because of its effect on odour the investment on the high-pressure sprayer is more beneficial. The amount of water used in spraying is so small that the floors do not get wet. Therefore, there will be no extra water running to the slurry gutters.

The measured odour annoyance from spreading of the treated liquid fraction was significantly lower than that of the raw slurry.

The initial reading of the olfactometer at the start of spreading was 60 (maximum reading) for both the treated liquid fraction and the raw slurry. The odour of the treated liquid fraction vanished in about 30 minutes while for the odour from raw slurry the time was the double, about 60 minutes, Figure 7. 


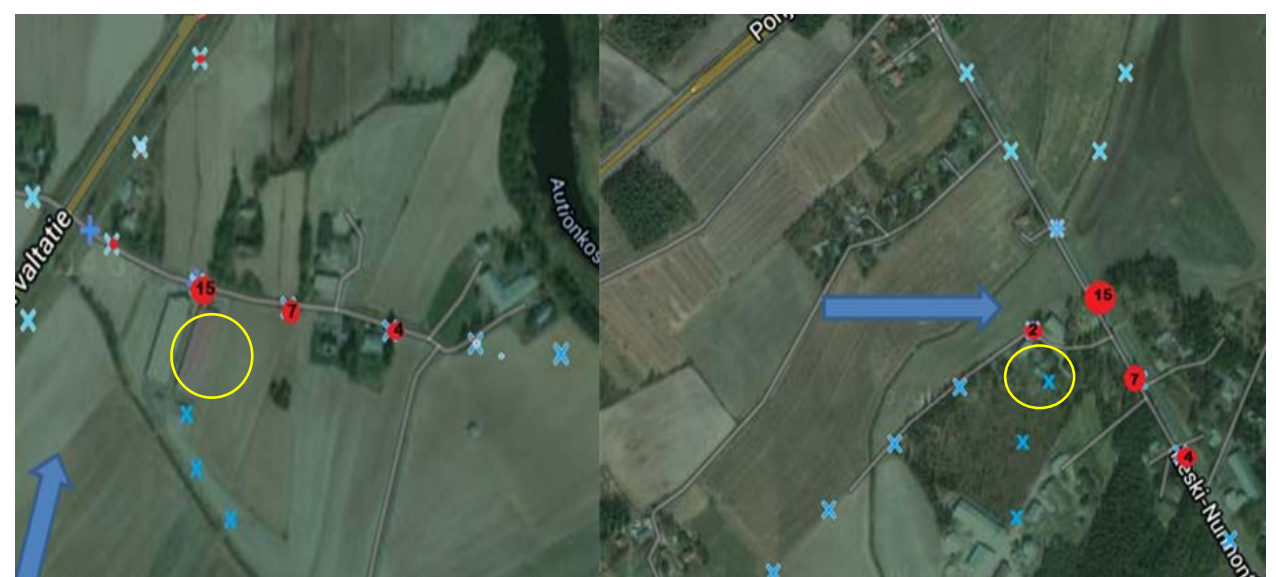

Figure 5. Odour emission detected by the panelists from the broiler farm (left) and from the swinery (right). The source of odour is inside the yellow circle. The size and the number inside the red dot indicate the average odour concentration according to the reading of the dial plate of the olfactometer. Red dot without a number indicates odour concentration less than 2 .

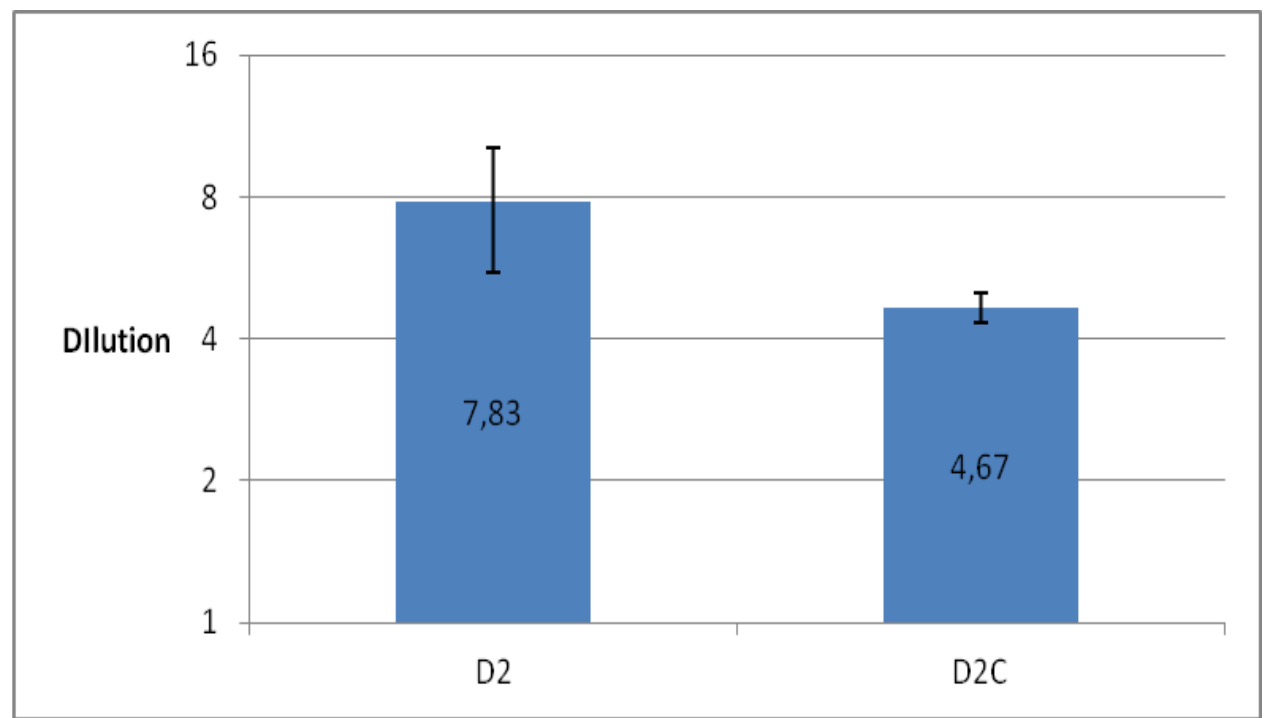

Figure 6. Odour reduction of high-pressure water spraying in a swinery. D2=without spraying, D2C=with spraying.

Also the character of the odour for the treated liquid fraction was less annoying. According to the assessment of the test persons the odour was more like the odour of soil or wet straw than that of manure. 

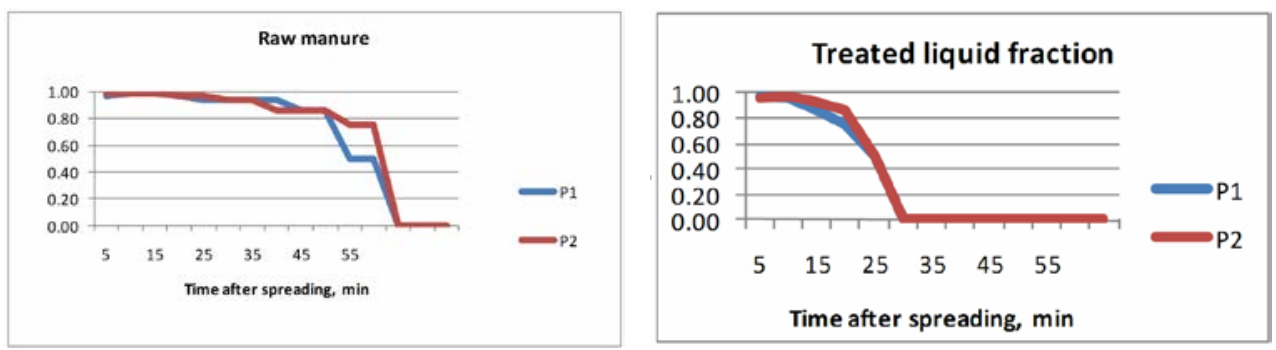

Figure 7. Reduction of odour after manure spreading. Raw slurry (left) and treated liquid fraction (right). Calculated as relative odor where initial odour is 1.0. P1 and P2 are the different observers.

\section{CONCLUSIONS}

The results on the use of portable field olfactometer on detecting odour on practical situations are positive and give valuable information on the effect of different technologies. The measurements performed so far are a good basis for further studies. More data is needed of the sensibility of the method to different weather conditions as they change between experiments and makes it difficult to compare the results of different techniques with each other. Also the number of panelists needed for different setups has to be studied further. Due to the disease risks of visitors the number of panelists used in measurements inside the production units has to be minimized. Besides that there has been also the difficulty of recruiting valid persons to the panels.

Also further studies are needed to gather wider and deeper evidence of the effect of different technologies on odour and to calculate the economics of the use these technologies.

\section{ACKNOWLEDGEMENTS}

The author would like to thank Teknillis-Yhteiskunnallinen Tutkimussäätiö (Technical and Societal Research Foundation), Ministry of Agriculture and Forestry and the city of Seinäjoki for the financial support of these studies.

\section{REFERENCES}

Brandt, R.C., Adviento-Borbe, M.A.A., Elliott, H.A., E. F. Wheeler, E.F. (2011). Protocols for reliable field olfactometry odor evaluations. Applied Engineering in Agriculture. Vol. 27(3): 457-466 _ 2011. American Society of Agricultural and Biological Engineers. ISSN 0883-8542.

European Parliament and Council (2010). Directive 2010/75/EU on industrial emissions. http://eurex.europa.eu/LexUriServ/LexUriServ.do?uri=OJ:L:2010:334:0017:0119:en:PDF

Hellstedt, M., Haapala. H. (2014). Animal production farms in the transition zone of urban and rural areas. Proceedings of International Conference of Agricultural Engineering. Zürich. July 6-10. 2014. 6 p.

Hügle, T., Andree, H. (2001). Temperature and odour emissions from liquid manure. Landtechnik 56(1): 36-38

Nasal Ranger 2013. Nasal Ranger operation manual vers 6.2. http://www.nasalranger.com. 
Santonja, G.G., Georgitzikis, K., Scalet, B.M., Montobbio, P., Roudier, S., Delgado Sancho, L. (2017). Best Available Techniques (BAT) Reference Document for Intensive Rearing of Poultry and Pigs. JRC Science for Policy Report. EUR 28674 EN. 